\title{
Knowledge, attitudes and perceptions of stroke: a cross-sectional survey in rural and urban Uganda
}

\author{
Mark Kaddumukasa1*, James Kayima', Martin N. Kaddumukasa', Edward Ddumba², Levi Mugenyi', \\ Svetlana Pundik ${ }^{4}$, Anthony J. Furlan ${ }^{4}$, Martha Sajatovic ${ }^{5}$ and Elly Katabira ${ }^{1}$
}

\begin{abstract}
Background: Information regarding the increasing burden of non-communicable diseases such as stroke is largely unknown among the vulnerable communities. This analysis, which is part of a larger U.S. National Institute of Heathfunded Medical Education Partnership Initiative neurological disorder survey, assessed community knowledge and attitudes on stroke and stroke risk factors.

Methods: A population cross-sectional survey was conducted in urban and rural Mukono, district, central Uganda. Through the systematic sampling method, data were gathered from 377 adult participants who were interviewed about selected aspects of stroke knowledge, attitudes and perception using a pretested structured questionnaire.

Results: A total of 377 participants were enrolled ( $47 \%$ urban). The leading risk factors identified by the participants were stress (36.6\%) and hypertension (28.9\%) respectively. None of the study participants identified cigarette smoking as a stroke risk factor. Seventy six percent of the participants did not recognize stroke as a disease of the brain.
\end{abstract}

Conclusion: Stroke knowledge is poor in both rural and urban Uganda. Tailored public health approaches that improve stroke awareness, knowledge and self management approaches are urgently needed to develop effective preventive measures and community response to stroke.

Keywords: Stroke, Knowledge, Risk factors, Warning factors

\section{Background \\ Background/rationale}

Stroke is one of the leading causes of mortality and morbidity worldwide with developing countries accounting for $85 \%$ of global deaths from stroke [1-4]. The lack of correct medical information and poor control of stroke risk factors contributes significantly to the rising incidence of stroke amongst Africans [5, 6]. Community attitudes and knowledge influence stroke prevention including risk factor identification and management as well as community and individual response to stroke symptoms when they occur. The success of primary

\footnotetext{
*Correspondence: kaddumark@yahoo.co.uk

1 Department of Medicine, School of Medicine, Makerere University

College of Health Sciences, P.O. Box 7072, Kampala, Uganda

Full list of author information is available at the end of the article
}

preventive measures and timely medical attention immediately following a stroke is influenced by the public's knowledge and perception of stroke and its risk factors $[5,7]$. Few studies have been conducted in sub-Saharan Africa, with over half of them in Nigeria. However the awareness of stroke, and its risk factors and symptoms is low in community studies conducted in African studies $[8,9]$. While in Nigerian studies among university staff, students and health workers, the awareness of stroke risk factors was high $[5,6]$.

In Uganda, the public's understanding and beliefs of stroke, its warning signs and associated risk factors have not been well studied. Nakibuuka and colleagues [10] recently conducted a survey on stroke risk factors and warning signs in community-dwelling individuals. This study [10] found that nearly $3 / 4$ of study participants were unable to identify stroke risk factors and warning 
signs and did not recognize stroke as a brain disorder [10]. Understanding the knowledge gaps and perceptions of stroke are critical to inform and lead to the development of appropriate targeted health promotion campaigns to prevent stroke among high risk populations in our setting. This study objectives were therefore to assess the knowledge and perceptions of stroke among urban and rural populations in Mukono district, central Uganda. This assessment, was part of larger study on neurological disorder knowledge and attitudes, provided context on how the community perceived neurological disorders more broadly.

\section{Methods}

\section{Study design and population}

This study was part of a larger U.S. National Institute of Heath-funded Medical Education Partnership Initiative (MEPI) neurological disorder survey, where we assessed community knowledge and attitudes on stroke and stroke risk factors among some of the study participants.

This was a cross-sectional study conducted within an ongoing population survey of 3000 participants on prevalence and incidence of neurological diseases in Mukono district. Face to face interviews were conducted between August and November 2014. Multistage stratified sampling technique was used as described below [11]. At the subcounty level, urban Mukono Town Council (TC) was randomly selected and Nakisunga sub-county as rural were randomly selected out of 13 sub-counties. Mapping of the selected urban and rural areas was based on the Uganda Population and Housing census where 11,373 and 9570 households were identified in Mukono TC and Nakisunga respectively [12]. The sampling frame was all households in these areas. Systematic sampling was used to select households in each village to total 2000 in the urban area and 2200 in the rural area that would participate in the large population survey. Out of the 1500 participants in the urban area and 1500 in the rural area, systematic sampling technique was used to select every tenth household for this interview. If the selected household objected participation, then the next household would be considered. A total of 377 participants participated in this study with 177 and 200 from the urban and rural areas, respectively. They were interviewed on selected aspects of stroke knowledge, attitudes and perception. The Inclusion criteria included; usual resident who is present in the sampled household on the night before the survey, aged 18 years or older (adult) and willingness to provide informed consent. We excluded those who were physically unable to undergo interview. One adult, randomly selected from each household was approached and consented, participated in the study. Only one participant was randomly selected from each household using simple random method. We employed randomly selected cards by the potential participants written on "Yes" and "No" for study participation. If similar cards were drawn then the process would be repeated until one participant was selected. The selected households were visited by the research team. The randomly selected participant was informed about the research and the intended use of the information obtained. A request for a written informed consent was then sought. To address potential sources of bias, a standardised questionnaire was used with a wide range of responses for the study participants which were read to the participants. The study interviewers received trained on the study protocols for data collection in order to minimize interobserver variability during data gathering and entering data.

\section{Sample size determination}

The sample size calculation for stroke knowledge and attitudes was based on the prevalence of hypertension which us an important risk factor for stroke. The sample size was calculated using formula: $\left\{n=\frac{Z_{\alpha}^{2}(p q)}{d^{2}}\right\}$ where $\mathrm{p}=$ prevalence of hypertension, $\mathrm{q}=$ complement of the prevalence, margin of error is error $=\mathrm{d}, \alpha=$ significance level. Setting significance at 0.05 and error margin at $5 \%$, adjusted sample requirement for an assumed $10 \%$ level of non-response $(\mathrm{nr}=10 \%)=\mathrm{N}^{*}$. Based on a previous study in Mukono [13] where hypertension prevalence was $27 \%$ and $\mathrm{N}^{*}=336$, we recruited 370 participants.

\section{Questionnaire and measurements}

We used a modified standardized questionnaire that assessed knowledge and attitudes towards stroke already used in the sub-Sahara African settings [5, 10, 14] (see Additional file 1). Participant's knowledge of stroke warning signs was categorized based on the numbers of stroke warning signs $[15,16]$. Individuals with good knowledge could identify 5-10 stroke warning signs, fair knowledge 2-4 signs, and poor knowledge one stroke warning sign. A similar categorization was used for participant's knowledge of stroke risk factors.

\section{Ethical considerations}

Ethical approval for the study was obtained from Makerere University College of Health Sciences' School of Medicine review board and ethics committee Ref number 2013-145 and UNCST Ref Number. HS 1551. Written informed consent was obtained before enrolling the participants into the study.

\section{Data analysis}

Descriptive statistics of mean, frequency, and percentages were used to summarise data on socio-demographic 
variables and stroke knowledge and perceptions. Chi square or Fisher's exact tests were used as appropriate to assess associations between stroke knowledge and perception and demographic variables and self-reported risk factors. Logistic regression was used to determine predictors of knowing the organ affected by stroke, good level of knowledge of stroke warning signs and risk factors. All tests of hypothesis were two tailed with a level of significance at 0.05 . All statistical analysis was performed using STATA software version 12 (Stata Corporation, College Station, TX, USA).

\section{Results}

A total of 377 study participants with the urban settings contributing 177 (47\%) adults were enrolled into this study. Sixty eight percent (260/377) of the study participants were women with a median age (IQR) of 34 (26$48)$ years. The age of the study participants ranged from 18-85 years. Other demographics are shown in Table 1. The number of study participants who correctly reponsed to the study questions is shown in Fig. 1.

Table 1 Demographic characteristics of the study participants $(\mathbf{N}=\mathbf{3 7 7})$

\begin{tabular}{ll}
\hline Characteristic & \\
\hline Median age in years (IQR) & $34(26-48)$ \\
Age range in years (min, max) & $18-85$ \\
Age categories in years, $\mathrm{n}(\%)$ & \\
$<25$ & $74(19.7)$ \\
$25-34$ & $123(32.8)$ \\
$35-44$ & $66(17.6)$ \\
$>44$ & $112(29.9)$ \\
Gender, $\mathrm{n}(\%)$ & \\
$\quad$ Male & $117(32.0)$ \\
\hline
\end{tabular}

\section{Organ affected by stroke and risk factors}

Only $24 \%(90 / 377)$ of participants correctly identified stroke as a disorder of the brain. The majority $(59.4 \%)$ did not have any idea of the organ affected by stroke. Nearly $16 \%(59 / 377)$ thought that the heart is the site of stroke (Table 2). Two hundred and seven participants (73.4 \%) knew at least one risk factor for stroke (Fig. 2). The most common risk factor identified by 138 (36.6 \%) participants was stress ( $43 \%$ urban; $31 \%$ rural; $\mathrm{P}=0.016$ ) followed by hypertension 109 (28.9 \%; 36 \% urban; $23 \%$ rural; $\mathrm{P}=0.004)$. No participants identified cigarette smoking as a stroke risk factor.

Recognizing stroke as a disorder of the brain was not, however, associated with knowledge of stroke warning signs, $\mathrm{P}=0.746$. Using a simple logistic regression, identifying stroke as a brain disorder was associated with knowing that stroke is preventable, possibly recurrent, that early treatment can prevent stroke with $\mathrm{p}$ values of 0.002, 0.01 and 0.005 respectively. Knowing that stroke can be prevented if treated early and if a person can have more than one stroke were not associated with knowledge regrading stroke risk factors. with $\mathrm{p}$ values; 0.280 and 0.138 , respectively.

\section{Warning symptoms of stroke}

Two hundred and fifteen participants (57 \%) knew no stroke warning signs or symptoms (Fig. 3). Eighteen percent (69/377) reported paralysis as the leading warning sign of stroke, followed by body weakness $12 \%$, (45/377); numbness $10 \%$ (38/377) respectively. Of the $162(43 \%)$ that knew stroke warning signs, 84 (52\%) knew 1 warning sign, 76 (47 \%) knew 2-4 warning signs, and $2(1 \%)$ knew five or more warning signs (Table 3). At multivariable logistic regression, we analysed for the factors associated with knowledge of stroke warning signs. Residence of the study

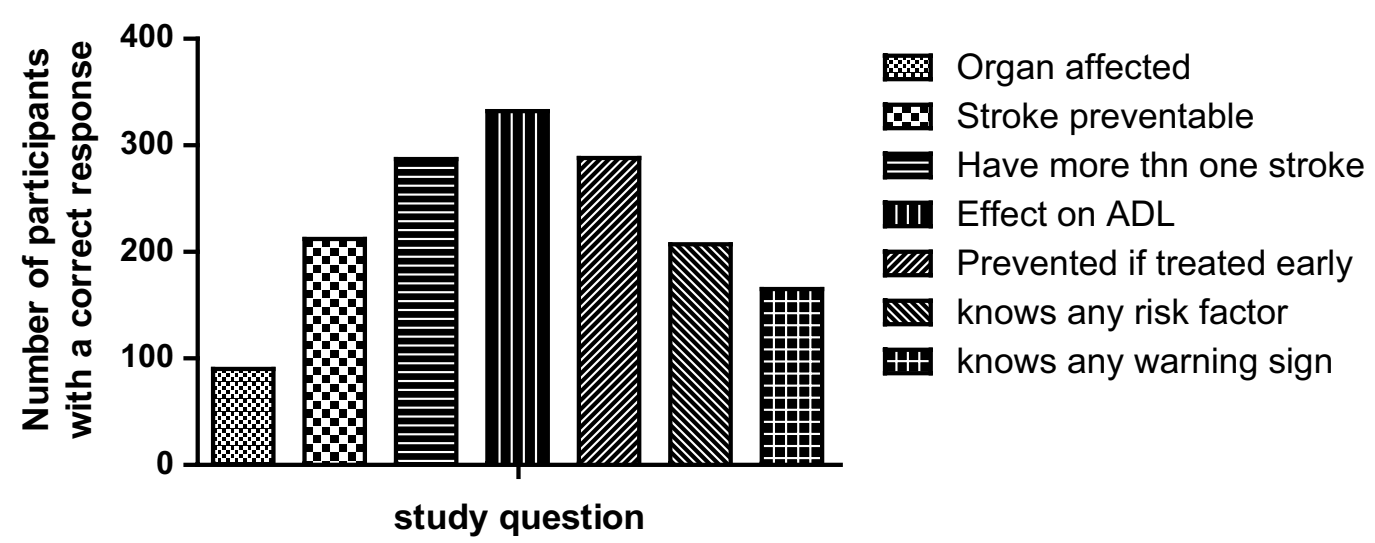

Fig. 1 Shows the number of study respondents with the correct answers to the study questions. Less than one-third of the study respondents correctly knew the brain as the site affceted by stroke 
Table 2 Knowledge of stroke disease $(\mathrm{N}=377)$

\begin{tabular}{|c|c|}
\hline Study question & N (\%) \\
\hline \multicolumn{2}{|c|}{ Organ of the body affected by stroke } \\
\hline Brain & $90(23.9)$ \\
\hline Heart & $59(15.7)$ \\
\hline Lungs & $4(1.1)$ \\
\hline Liver & $0(0)$ \\
\hline Don't know & $224(59.4)$ \\
\hline \multicolumn{2}{|c|}{ Is stroke preventable } \\
\hline Yes & $212(56.2)$ \\
\hline No & $83(22.0)$ \\
\hline Don't know & $82(21.8)$ \\
\hline \multicolumn{2}{|c|}{ Can one have stroke more than once } \\
\hline Yes & $287(76.1)$ \\
\hline No & $31(8.2)$ \\
\hline Don't know & $59(15.7)$ \\
\hline \multicolumn{2}{|c|}{$\begin{array}{l}\text { Does stroke have an effect on daily activities like driving } \\
\text { a car, dressing, having job etc }\end{array}$} \\
\hline Yes & $332(88.1)$ \\
\hline No & $14(3.7)$ \\
\hline Don't know & $31(8.2)$ \\
\hline \multicolumn{2}{|c|}{ Can stroke be prevented if treated early } \\
\hline Yes & $288(76.4)$ \\
\hline No & $21(5.6)$ \\
\hline Don't know & $68(18.0)$ \\
\hline \multicolumn{2}{|c|}{ Knows any risk factors for stroke } \\
\hline Yes & $207(54.9)$ \\
\hline No & $10(2.7)$ \\
\hline Don't know & $160(42.4)$ \\
\hline \multicolumn{2}{|c|}{ Knows any warning factors for stroke } \\
\hline Yes & $165(43.8)$ \\
\hline No & $18(4.8)$ \\
\hline Don't know & $194(51.5)$ \\
\hline
\end{tabular}

participants with $\mathrm{P}$ value of 0.04 with adjusted OR (95\% CI) of $1.72(1.03-2.90)$ and knowing that stroke is preventable, $\mathrm{P}$ value $=0.07$; adjusted OR $(95 \% \mathrm{CI})$, 0.08 (0.04-0.15) remained statistically significant. While knowing any risk factor for stroke was not associated with the knowledge of stroke warning signs, $\mathrm{P}$ value $=0.133$.

\section{Stroke prevention, recurrence, and effect on activities of daily living}

More than half of particiapants $56 \%(212 / 377)$ reported that stroke is preventable. Nearly two-thirds (76 \%, 287/377) believed that stroke can be recurrent. Eighty eight percent of participants (332/377) reported that stroke can have an effect on daily activities like driving a car, dressing, and having a job.

\section{Discussion}

This survey of stroke knowledge and attitudes conducted in urban and rural Uganda found that many individuals have extremely limited knowledge of risk factors for stroke, are not aware that stroke is a brain disease, and are not familiar with many of the common early warning signs and symptoms of stroke. Individuals residing in rural setting were most likely to be poorly informed about stroke. The findings of this report are very much in line with another recent report also conducted in the Ugandan setting (10). Majority of the study participants were young which is in keeping with the Ugandan population structure with a median age of 15.6 years [12].

With the rising burden of non-communicable diseases in sub-Saharan Africa, there is a need to develop strategies to prevent them. Lack of knowledge or incorrect knowledge of stroke risk factors and lack of awareness of the warning signs contributes to the rising incidence of stroke amongst Africans $[5,14]$. The dissemination of accurate information regarding stroke risk factors and warning signs is important to prevent stroke morbidity and fatality within vulnerable communities. Increasing stroke knowledge among communities is known to result in a shorter time of presentation to the emergency department following stroke onset [17].

None of the study participants identified smoking as an important risk factor for stroke yet smoking has been reported as an important risk factor. Second hand smoke has also been reported to increase the odds of stroke by six fold [18, 19]. The Ugandan national prevalence of smoking has been rising to currently $16.6 \%$ [20]. Providing correct information regarding smoking addressing its relationship with stroke and other chronic diseases would be key within our communities.

Stress was reported as the leading cause of stroke more in the urban populations than rural. Stress is associated with cardiovascular disease and metabolic syndromes all which increase the risk of strokes [21, 22]. Identifying personal stressors and addressing them is critical in reducing this risk.

Our study reports that only $47.2 \%$ individuals knew at least one of the known risk factors of stroke. This is comparable to other studies performed else where $[5,10$, 23]. In these other reports less knowledgable individuals tended to be from poorer communities and had less education. In our analysis, rural residents, where education and income levels are generally expected to be lower, had less stroke awareness. Only $28.9 \%$ of the study participants cited hypertension as a stroke risk factor. Hypertension, is one of the most important risk factors for stroke [24]. This is slightly lower than earlier studies which have reported higher proportions of $32-51 \%$ in the general public $[16,25-29]$. The identification of hypertension, in 


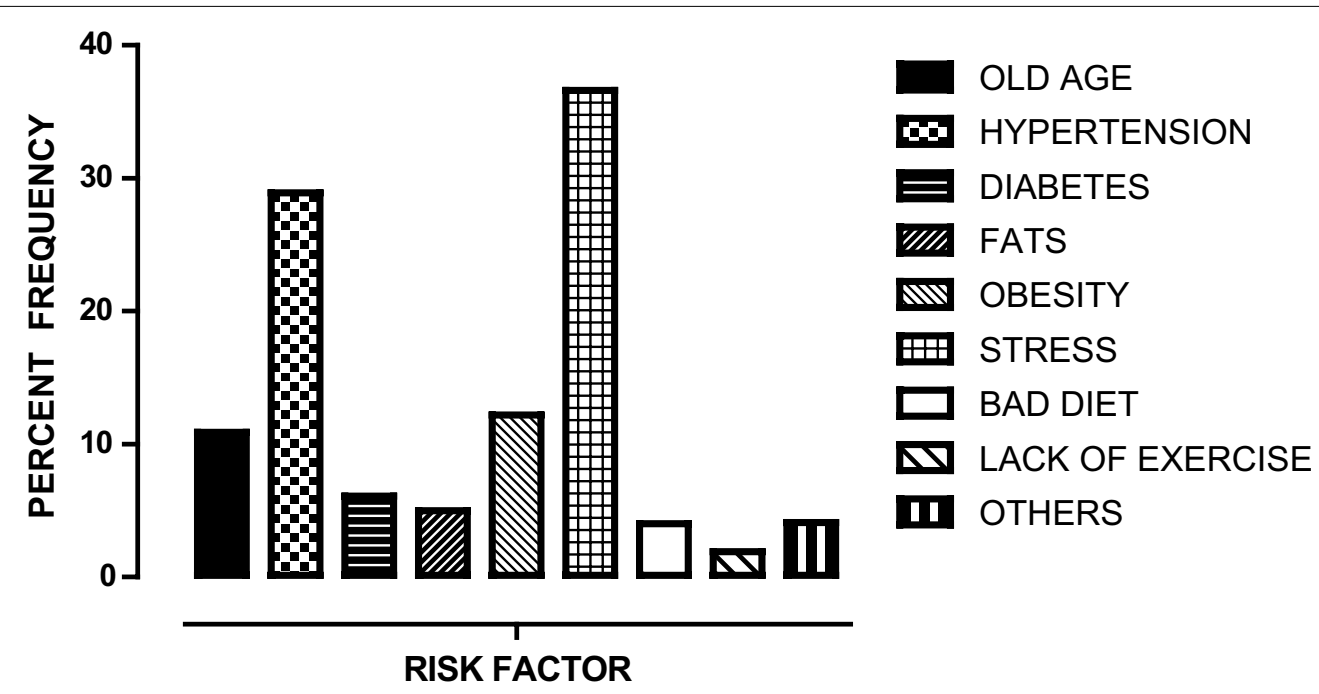

Fig. 2 Shows the frequency of reported known risk factors among the study participants. Stress was the leading known risk factor reported followed by hypertension by the study respondents

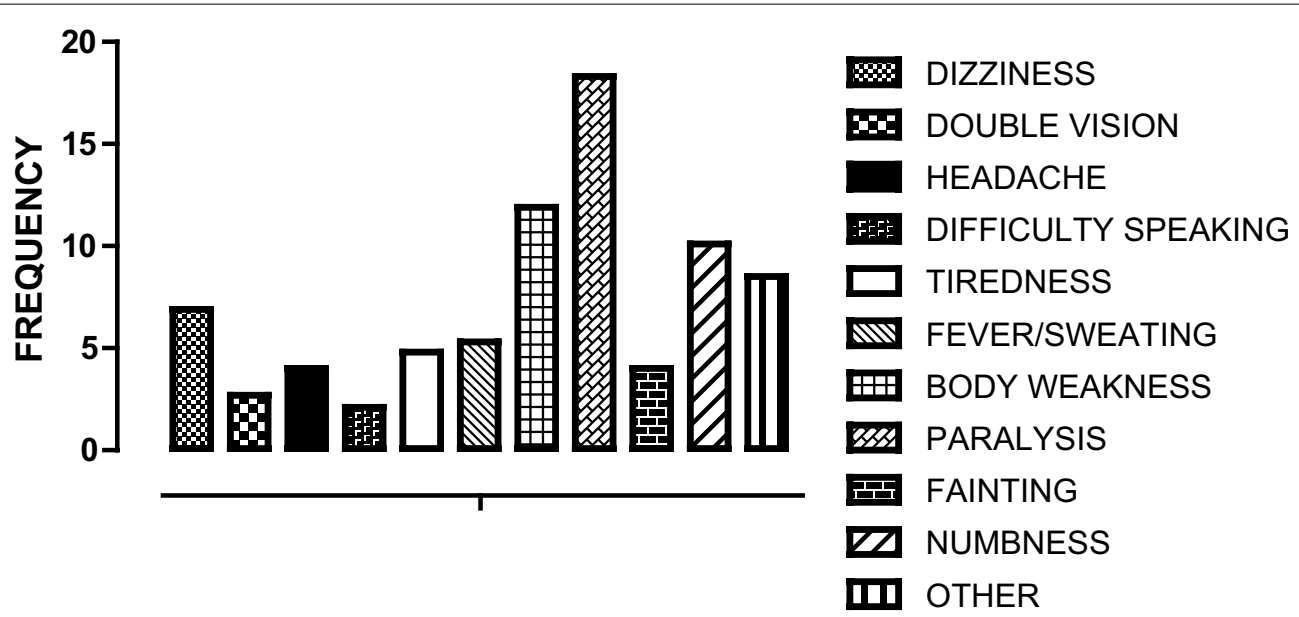

Fig. 3 Shows the knowledge for the warning signs of stroke among the study participants. Paralysis and body weakness were the common warning signs reported by the study participants

these earlier studies may be attributed to the differences in health care systems, awareness among these populations. Nevertheless, considering the intimate relationship between hypertension and stroke, future stroke awareness campaigns and health education need to emphasize the significance of hypertension. While the lack of stroke knowledge in our sample is daunting, it also provides an opportunity to spur action, and can inform stroke awareness campaigns in Uganda [30]. Tailored stroke public health campaigns are essential for Ugandan rural adults to enhance their knowledge regarding stroke symptomatology and risk factors. These tailored campaigns should include packages of self management approaches and key messages as only increasing knowledge regarding stroke alone has been found to be ineffective if there is no reinforcement [31-33]. This will help them in the future to reduce stroke risk, identify stroke should it occur, and mobilize individuals and the community to respond appropriate to stroke early warning signs. Finally, identifying high-risk sub-groups (for example, individuals with severe and poorly controlled hypertension) and instituting appropriate measures might help mitigate the rising threats of stroke in Uganda and sub Saharan Africa.

\section{Limitations}

Our study is limited by the fact that it was cross-sectional, used close-ended questions, and was confined to a fairly limited geographic area. This might have limited the 
Table 3 Factors associated with knowledge for warning signs of stroke

\begin{tabular}{|c|c|c|c|}
\hline & $\begin{array}{l}\text { Knows one or more } \\
\text { warning signs for stroke, N (\%) }\end{array}$ & $\begin{array}{l}\text { Don't know any warning } \\
\text { sign for stroke, } \mathrm{N}(\%)\end{array}$ & $\mathbf{P}$ \\
\hline \multicolumn{4}{|l|}{ Residence } \\
\hline Rural & $76(46.9)$ & $124(57.7)$ & \multirow[t]{2}{*}{0.038} \\
\hline Urban & $86(53.1)$ & $91(42.3)$ & \\
\hline \multicolumn{4}{|l|}{ Age in years } \\
\hline$<25$ & $30(18.6)$ & $44(20.6)$ & \multirow[t]{4}{*}{0.331} \\
\hline $25-34$ & $46(28.6)$ & $77(36.0)$ & \\
\hline $35-44$ & $32(19.9)$ & $34(15.9)$ & \\
\hline$>44$ & $53(32.9)$ & $59(27.6)$ & \\
\hline \multicolumn{4}{|l|}{ Sex } \\
\hline Male & $48(30.8)$ & $69(32.9)$ & \multirow[t]{2}{*}{0.672} \\
\hline Female & $108(69.2)$ & $141(67.1)$ & \\
\hline \multicolumn{4}{|c|}{ Stroke preventable } \\
\hline Yes & $83(51.2)$ & $129(60.0)$ & \multirow[t]{3}{*}{0.000} \\
\hline No & $61(37.7)$ & $22(10.2)$ & \\
\hline Don't know & $18(11.1)$ & $64(29.8)$ & \\
\hline \multicolumn{4}{|c|}{ Person can have stroke more than once } \\
\hline Yes & $135(83.3)$ & $152(70.7)$ & \multirow[t]{3}{*}{0.000} \\
\hline No & $18(11.1)$ & $13(6.1)$ & \\
\hline Don't know & $9(5.6)$ & $50(23.3)$ & \\
\hline \multicolumn{4}{|c|}{ Stroke has effect on daily activities } \\
\hline Yes & $155(95.7)$ & $177(82.3)$ & \multirow[t]{3}{*}{0.000} \\
\hline No & $4(2.5)$ & $10(4.7)$ & \\
\hline Don't know & $3(1.9)$ & $28(13.0)$ & \\
\hline \multicolumn{4}{|c|}{ Stroke can be prevented if treated early } \\
\hline Yes & $130(82.3)$ & $158(73.5)$ & \multirow[t]{3}{*}{0.068} \\
\hline No & $11(6.8)$ & $10(4.7)$ & \\
\hline Don't know & $21(13.0)$ & $47(21.9)$ & \\
\hline \multicolumn{4}{|c|}{ Knows risk factors for stroke } \\
\hline 3 or more & $31(19.1)$ & $10(4.7)$ & \multirow[t]{3}{*}{0.000} \\
\hline 1 or 2 & $115(80.0)$ & $63(29.3)$ & \\
\hline Don't know & $16(9.9)$ & $142(66.1)$ & \\
\hline \multicolumn{4}{|c|}{ Knows Organ affected by stroke } \\
\hline Yes & $40(24.7)$ & $50(23.3)$ & \multirow[t]{2}{*}{0.746} \\
\hline No & $122(75.3)$ & $165(76.7)$ & \\
\hline
\end{tabular}

responses regarding knowledge and attitudes to stroke omiting some of the respondents' responses. However, the survey questions were worded such that the answer choices covered a wide range of response possibilities and findings seem to confirm similar data obtained in another recent study on stroke awareness in Uganda.

\section{Conclusion}

Future stroke awareness strategies should emphasize that stroke is a brain disease, that it is preventable, and help individuals to understand and manage stroke risk factors.
Considering the importance of prompt treatment in improving patient outcomes, we must continue to advise individuals and communities with regard to appropriate action during emergencies. Finally, the most important implication of the present study is the need to focus on primary and secondary prevention, and crucially, target low-income high risk subjects.

\section{Additional file}

Additional file 1. The study questionnaire. 


\section{Abbreviations}

TC: town council; MEPI: medical education partnership initiative.

\section{Authors' contributions}

MK, ED, JK and MNK collected data during the survey; IM and EK performed data analyses; MS, SP, AF and EK designed the study; IM, MK, JK, and MS wrote the paper. MS, AF, SP and EK revised the manuscript for important intellectual content. All authors discussed the results and commented on the manuscript. All authors read and approved the final manuscript.

\section{Author details}

${ }^{1}$ Department of Medicine, School of Medicine, Makerere University College of Health Sciences, P.O. Box 7072, Kampala, Uganda. ${ }^{2}$ Department of Medicine, St Raphael of St Francis Nsambya Hospital, Nkozi University, P.O. Box 7146, Kampala, Uganda. ${ }^{3}$ Infectious Diseases Research Collaboration, Mulago Hill Road, MUJHU3 Building, P.O. Box 7475, Kampala, Uganda. ${ }^{4}$ University Hospitals Case Medical Center, Neurological Institute Case Western Reserve University, 11100 Euclid Avenue, Cleveland, OH 44106, USA. ${ }^{5}$ Neurological and Behavioral Outcomes Center, University Hospitals Case Medical Center, 11100 Euclid Avenue, Cleveland, $\mathrm{OH}$ 44106, USA.

\section{Acknowledgements}

This study was supported by the National Institute of Neurological Disorders and Stroke of the National Institute of Health under MEPI—Neurology linked award number R25NS080968. We thank Levi Mugenyi for the guidance on the statistical analysis and Doreen Birungi for the support and guidance. We also thank our survey subjects for participating in this study.

\section{Competing interests}

The authors declare that they have no competing interests.

Received: 13 May 2015 Accepted: 17 December 2015

Published online: 26 December 2015

\section{References}

1. Feigin VL, Forouzanfar MH, Krishnamurthi R, Mensah GA, Connor M, Bennett DA, Moran AE, Sacco RL, Anderson L, Truelsen T, et al. Global and regional burden of stroke during 1990-2010: findings from the global burden of disease study 2010. Lancet. 2010;383(9913):245-54.

2. Mathers CD, Lopez AD, Murray CJL. The burden of disease and mortality by condition: data, methods, and results for 2001. In: In Lopez AD, Mathers CD, Ezzati M, editors. Global burden of disease and risk factors, chap 3. Washington, DC: World Bank; 2006.

3. Strong K, Mathers C, Bonita R. Preventing stroke: saving lives around the world. Lancet Neurol. 2007;6(2):182-7.

4. Krishnamurthi RV, Feigin VL, Forouzanfar MH, Mensah GA, Connor M, Bennett DA, Moran AE, Sacco RL, Anderson LM, Truelsen T, et al. Global and regional burden of first-ever ischaemic and haemorrhagic stroke during 1990-2010: findings from the global burden of disease study. Lancet Glob Health. 2010;1(5):e259-81.

5. Akinyemi RO, Ogah OS, Ogundipe RF, Oyesola OA, Oyadoke AA, Ogunlana MO, Otubogun FM, Odeyinka TF, Alabi BS, Akinyemi JO, et al. Knowledge and perception of stroke amongst hospital workers in an African community. Eur J Neurol. 2009;16(9):998-1003.

6. Obembe AO, Olaogun MO, Bamikole AA, Komolafe MA, Odetunde MO. Awareness of risk factors and warning signs of stroke in a Nigeria university. J Stroke Cerebrovasc Dis. 2014;23(4):749-58.

7. Jones SP, Jenkinson AJ, Leathley MJ, Watkins CL. Stroke knowledge and awareness: an integrative review of the evidence. Age Ageing. 2010;39(1):11-22.

8. Cossi MJ, Preux PM, Chabriat H, Gobron C, Houinato D. Knowledge of stroke among an urban population in Cotonou (Benin). Neuroepidemiology. 2012;38(3):172-8.

9. Wahab KW, Okokhere PO, Ugheoke AJ, Oziegbe O, Asalu AF, Salami TA. Awareness of warning signs among suburban Nigerians at high risk for stroke is poor: a cross-sectional study. BMC Neurol. 2008;8:18.
10. Nakibuuka J, Sajatovic M, Katabira E, Ddumba E, Byakika-Tusiime J, Furlan AJ. Knowledge and perception of stroke: a population-based survey in Uganda. ISRN Stroke. 2014;2014:309106.

11. Kish Leslie (Ed.). Survey Sampling. New York Wiley: 1965.

12. UBOS. Uganda population and housing census, statistical abstract. Kampala: Uganda bureau of statistics 2011.

13. Musinguzi G, Nuwaha F. Prevalence, awareness and control of hypertension in Uganda. PLoS One. 2013;8(4):e62236.

14. Droste DW, Safo J, Metz RJ, Osada N. Stroke awareness in luxemburg: deficit concerning symptoms and risk factors. Clin Med Insights Cardiol. 2014;8(Suppl 2):9-13.

15. Ayanniyi O, Akande O, Mustapha AF. Knowledge and perception of stroke among adults in Osogbo, Nigeria. Afr J Med Med Sci. 2006;35(4):447-52.

16. Sug Yoon S, Heller RF, Levi C, Wiggers J, Fitzgerald PE. Knowledge of stroke risk factors, warning symptoms, and treatment among an Australian urban population. Stroke. 2001;32(8):1926-30.

17. Alberts MJ, Perry A, Dawson DV, Bertels C. Effects of public and professional education on reducing the delay in presentation and referral of stroke patients. Stroke. 1992;23(3):352-6.

18. Bonita R, Duncan J, Truelsen T, Jackson RT, Beaglehole R. Passive smoking as well as active smoking increases the risk of acute stroke. Tob Control. 1999;8(2):156-60.

19. CDC. 1986 Surgeon General's report: the health consequences of involuntary smoking. MMWR Morb Mortal Wkly Rep. 1986;35(50):769-70.

20. Global youth tobacco survey (GYTS). The Uganda global youth tobacco survey REPORT (2008) — tobacco control policy implications. Geneva: $\mathrm{WHO} ; 2008$.

21. Everson-Rose SA, Lewis TT. Psychosocial factors and cardiovascular diseases. Annu Rev Public Health. 2005;26:469-500.

22. Tsutsumi A, Kayaba K, Kario K, Ishikawa S. Prospective study on occupational stress and risk of stroke. Arch Intern Med. 2009;169(1):56-61.

23. Kothari R, Sauerbeck L, Jauch E, Broderick J, Brott T, Khoury J, Liu T. Patients' awareness of stroke signs, symptoms, and risk factors. Stroke. 1997;28(10):1871-5.

24. Feinberg WM. Primary and secondary stroke prevention. Curr Opin Neurol. 1996;9(1):46-52.

25. Potvin L, Richard L, Edwards AC. Knowledge of cardiovascular disease risk factors among the Canadian population: relationships with indicators of socioeconomic status. CMAJ. 2000;162(9 Suppl):S5-11.

26. Hux K, Rogers T, Mongar K. Common perceptions about strokes. J Community Health. 2000;25(1):47-65.

27. Reeves MJ, Hogan JG, Rafferty AP. Knowledge of stroke risk factors and warning signs among Michigan adults. Neurology. 2002;59(10):1547-52.

28. Schneider AT, Pancioli AM, Khoury JC, Rademacher E, Tuchfarber A, Miller R, Woo D, Kissela B, Broderick JP. Trends in community knowledge of the warning signs and risk factors for stroke. JAMA. 2003;289(3):343-6.

29. Gill R, Chow CM. Knowledge of heart disease and stroke among cardiology inpatients and outpatients in a Canadian inner-city urban hospital. Can J Cardiol. 2010;26(10):537-40.

30. Al Hamarneh YN. Crealey GE, McElnay JC. Coronary heart disease: health knowledge and behaviour. Int. J Clin Pharm. 2011;33(1):111-23.

31. Forster A, Brown L, Smith J, House A, Knapp P, Wright JJ, Young J. Information provision for stroke patients and their caregivers. Cochrane Database Syst Rev. 2012;11:CD001919. doi:10.1002/14651858.CD001919.pub3.

32. Rasura M, Baldereschi M, Di Carlo A, Di Lisi F, Patella R, Piccardi B, Polizzi B, Inzitari D. Effectiveness of public stroke educational interventions: a review. Eur J Neurol. 2014;21(1):11-20.

33. Trobbiani K, Freeman K, Arango M, Lalor E, Jenkinson D, Thrift AG. Comparison of stroke warning sign campaigns in Australia, England, and Canada. Int J Stroke. 2013:8:28-31. 